\title{
Decomposição dos Efeitos das Mudanças nos Termos de Troca sobre a Indústria Brasileira no período de 2008 a 2014
}

\section{Decomposition of the Effects of the Terms of Trade Changes on the Brazilian Industry in the period from 2008 to 2014}

\author{
Karina Simone Sass* \\ Terciane Sabadini Carvalho** \\ Alexandre Alves Porsse $* * *$
}

\begin{abstract}
Resumo: Este artigo analisa os efeitos das variações dos termos de troca sobre a indústria em um período recente da economia brasileira (2008-2014). O objetivo é identificar os setores mais sensíveis a essas variações e os impactos na produção e no emprego. Utilizando-se um modelo de equilíbrio geral computável (EGC) dinâmico, realiza-se uma simulação histórica considerando os movimentos observados, no período compreendido entre 2008 e 2014, das principais variáveis macroeconômicas, incluindo-se as variações dos termos de troca. De maneira geral, os resultados indicam que os setores mais impactados são os intensivos em recursos naturais e mão de obra. Os resultados apontam também que a valorização dos termos de troca do período 2008-2011 não foi determinante para o desempenho setorial da indústria, enquanto que a queda ocorrida no período 2012-2014 se mostrou importante para o bom desempenho setorial da indústria.
\end{abstract}

Palavras-chave: Termos de troca. Análise setorial. Equilíbrio geral computável.

Abstract: This study analyses the effects of terms of trade changes on the industry in a recent period of the Brazilian economy (2008 to 2014). The goal is to identify the most sensitive industries to terms of trade and its impacts on production and sectoral employment. Using a dynamic computable general equilibrium (CGE) model, we have performed a historical simulation considering the observed values of the main macroeconomic variables including the terms of trade changes. Overall, the results indicated that the most affected sectors would be the ones related to heavy industry, natural resources intensive and labor intensive. The results also indicate that the terms of trade improvement in the period 2008-2011 was not relevant to the industry performance, while the terms of trade decrease in the period 2012-2014 was very important to the industrial performance.

Keywords: Terms of trade. Economy activity sectors. General equilibrium.

* $\quad$ Mestre em Desenvolvimento Econômico pelo Programa de Pós-Graduação em Desenvolvimento Econômico (PPGDE) da Universidade Federal do Paraná (UFPR). Doutoranda em Economia no Instituto de Pesquisas Econômicas da Universidade de São Paulo (USP). E-mail: karinasass@ gmail.com

** Doutora em Economia pelo Centro de Desenvolvimento e Planejamento Regional (Cedeplar) da Universidade Federal de Minas Gerais (UFMG). Professora adjunta do Departamento de Economia e do Programa de Pós-Graduação em Desenvolvimento Econômico (PPGDE) da Universidade Federal do Paraná (UFPR). E-mail: tersabadini@gmail.com

*** Doutor em Economia pela Universidade Federal do Rio Grande do Sul (UFRGS). Professor adjunto do Departamento de Economia e do Programa de Pós-graduação em Desenvolvimento Econômico (PPGDE) da Universidade Federal do Paraná (UFPR). E-mail: porsse@gmail.com 
JEL Classification: C68, D58, F19.

\section{Introdução}

As mudanças nos termos de troca (relação entre os preços dos bens exportados com os preços dos bens importados) desempenham um papel importante no cenário econômico de países em desenvolvimento, pois têm impacto direto sobre a competitividade externa e são elementos integrantes das estratégias de crescimento e desenvolvimento econômico. Identificar como as variações nos termos de troca influenciam os diversos setores de atividade econômica é importante para auxiliar na promoção do crescimento da produção e do emprego, assim como para direcionar políticas industriais.

O Brasil apresentou forte apreciação cambial real no período de 2007 a 2011 , que, segundo Oreiro e Marconi (2014), é decorrente da valorização dos termos de troca observada nos últimos anos, seguida por uma depreciação de 2012 a 2015. De acordo com Silva e Milani (2016), uma depreciação cambial contribui para o crescimento do setor industrial e favorece a competitividade no setor de manufaturados. Já uma apreciação cambial favoreceria a especialização em setores intensivos em recursos dotados de vantagens comparativas, desestimulando os setores que não apresentam essas vantagens, tais como a indústria de bens manufaturados (VERÍSSIMO; ARAÚJO, 2015).

Conforme apontado por Bresser-Pereira (2004), o câmbio, além de determinar exportações e importações, afeta o nível de salário real, o consumo e a poupança. Uma taxa de câmbio mantida competitiva ou depreciada mantém baixos os salários e o consumo e aumenta a poupança, criando oportunidades de investimentos, principalmente para a indústria exportadora. Desse modo, as variações na taxa de câmbio influenciam tanto o lado da demanda, pela alteração nos preços relativos, quanto o da oferta, através das mudanças que provocam nos salários reais e nos preços de bens importados.

Segundo Squeff e Araújo (2013), a taxa de câmbio real constitui uma variável determinante da heterogeneidade estrutural observada no Brasil. Segundo os autores, a elevada volatilidade e a tendência de apreciação dos últimos anos são benéficas para setores que possuem maior coeficiente de importações, que adquirem insumos produtivos ou máquinas e equipamentos do exterior, mas também pode significar perda de competitividade para os setores que competem com a produção estrangeira via preços.

Apesar de afetar diversos setores da economia, é sobre a indústria manufatureira que recaem os maiores efeitos da oscilação cambial e das mudanças nos termos de troca, especialmente quando ocorre uma apreciação. Segundo Marconi e Rocha (2015), a taxa de câmbio influi sobre o grau de competitividade externa de 
um país, em que um prolongado período de apreciação cambial pode prejudicar o saldo da balança comercial e a participação da manufatura no valor adicionado.

Devido à importância aos setores industriais, a taxa de câmbio frequentemente é analisada em estudos sobre o grau de industrialização no Brasil, inclusive a apreciação cambial é apontada como um dos principais elementos do processo de desindustrialização ${ }^{1}$ por Palma (2005) e Bresser-Pereira e Marconi (2008). Embora a relação entre taxa de câmbio e a (des)industrialização seja um tema bastante explorado na literatura nacional, ainda há necessidade de mais discussão empírica sobre o impacto nas diversas atividades econômicas e, em especial, na indústria.

Segundo Oreiro e Marconi (2014), o comportamento da taxa real de câmbio parece se relacionar com a dinâmica recente dos termos de troca da economia brasileira, indicando que as valorizações dos termos de troca parecem ser a causa principal da apreciação cambial e, consequentemente, da perda de competitividade da indústria brasileira. Desse modo, estudar os impactos das variações dos termos de troca pode auxiliar na compreensão do processo de desindustrialização da economia brasileira.

O debate sobre as transformações na estrutura produtiva da economia brasileira é pautado pela perda de participação da indústria de manufatura na matriz produtiva do país. De acordo com Lamonica e Feijó (2013), do pós-guerra até meados dos anos 1980, o peso do valor adicionado da indústria no PIB passou de $20 \%$, em 1947, para cerca de $36 \%$, em 1985, passando a cair desde então, chegando a $15 \%$ em 2010. Ainda segundo os autores, o crescimento relativamente menor da economia brasileira em relação a outros países em desenvolvimento poderia ser explicado em parte pela perda da importância da manufatura no PIB, indicativo de que a economia passa por um processo de desindustrialização. Convém observar que, durante os anos 90, a indústria brasileira passou por um processo de reestruturação produtiva caracterizado tanto pela desverticalização (terceirização) quanto também pela incorporação de novas tecnologias no processo produtivo devido à abertura comercial e apreciação cambial. De um lado, a desverticalização pode explicar parcialmente o fenômeno da chamada desindustrialização nos anos 90. De outro lado, as transformações das últimas décadas na economia brasileira associadas à apreciação cambial e valorização dos termos de troca podem não necessariamente ter gerado efeitos negativos sobre a atividade econômica, já que poderiam favorecer a competitividade industrial ao estimular a importação de máquinas e equipamentos mais avançados tecnologicamente.

1 O conceito de desindustrialização se refere a uma redução persistente da participação do emprego industrial no emprego total de um país ou região, assim como uma redução no valor adicionado como proporção do PIB. 
Embora exista uma relação entre valorização/desvalorização dos termos de troca com apreciação/depreciação do câmbio, a taxa de câmbio tem sido a variável central na discussão sobre industrialização, e não há evidências sobre o papel dos termos de troca nesse processo. Assim, como contribuição à literatura, este estudo tem por objetivo analisar o efeito de mudanças nos termos de troca sobre a atividade industrial. Adicionalmente, uma segunda contribuição diz respeito ao uso do método de análise de equilíbrio geral computável (EGC), o qual propicia realizar uma avaliação com maior desagregação setorial. Desse modo, a proposta deste trabalho é medir a sensibilidade da indústria às variações dos termos de troca e identificar os principais impactos dessas variações sobre os setores de atividade econômica do Brasil no período de 2008 a 2014. Através de um modelo de EGC dinâmico, calibrado com dados do Sistema de Contas Nacionais de 2007, é realizada uma simulação histórica considerando os movimentos das principais variáveis macroeconômicas observados no período. O impacto das variações observadas dos termos de troca no período é incluído na simulação e representa a diferença entre o índice de preços dos bens exportados e o índice de preços dos bens importados. Uma variação positiva (negativa) dos termos de troca em determinado ano está relacionada a uma apreciação (depreciação) da taxa de câmbio real no mesmo período.

Os resultados da simulação permitem observar o comportamento de variáveis como demanda, produção e nível de emprego setoriais nos períodos de maior valorização dos termos de troca (2008 a 2011) e desvalorização (2012 a 2014), isolando o efeito dos termos de troca das demais variáveis macroeconômicas observadas. As principais evidências encontradas com a simulação mostram que o desempenho industrial no período de 2008 a 2011 não foi muito afetado pela valorização dos termos de troca, sendo que, no período de 2012 a 2014, a desvalorização se mostrou mais relevante para o desempenho industrial.

Além desta introdução, este trabalho é composto por mais quatro seções: na seção 2 empõem-se, brevemente, as principais teorias e evidências empíricas acerca dos efeitos das oscilações dos termos de troca sobre a economia; na seção 3 apresentam-se o modelo EGC e o banco de dados utilizados; na seção 4 apresentam-se e discutem-se os resultados da simulação; e, por fim, na seção 5 tecem-se as considerações finais.

\section{Termos de Troca: Teoria e Evidências Empíricas}

A discussão teórica sobre a influência dos termos de troca e dos preços das commodities sobre variáveis macroeconômicas tomou forma a partir dos anos 50, quando surgiram na América Latina debates que se propuseram a analisar as relações da região com o resto do mundo. A principal teoria proposta nessa 
época, e que dá grande ênfase ao papel das variações dos termos de troca sobre a economia latino-americana, é a tese da deteorioração dos termos de troca, ou tese de Prebisch-Singer (P-S), desenvolvida independentemente por Prebisch (1950) e Singer (1950). A tese P-S afirma que se deve esperar uma deterioração secular dos termos de troca entre produtos primários e produtos manufaturados (GONÇALVES; BARROS, 1982). O debate sobre a deterioração dos termos de troca teve destaque durante o processo de industrialização de diversos países da América Latina, incluindo o Brasil, pois os países periféricos (em desenvolvimento) exportam bens essencialmente agrícolas e importam bens industrializados. A alta elasticidade-renda dos primeiros faria com que, para manter o equilíbrio externo dos países periféricos, os termos de troca tivessem de cair ao longo do tempo, logo, para desenvolver internamente a indústria, os países periféricos deveriam vencer obstáculos quase que intransponíveis (MARÇAL, 2006).

A tese da deterioração dos termos de troca foi uma das justificativas teóricas do processo de industrialização por substituição de importações posto em prática por diversos países latino-americanos. Segundo Marçal (2006), uma das conclusões da tese P-S, em termos de política econômica, afirma que os países em desenvolvimento deveriam tentar evitar participar dos fluxos de comércio internacional e procurar se capacitar na produção de produtos industrializados. Assim, a estratégia de industrialização via substituição de importações seria uma decorrência dessa conclusão.

Devido à influência de que a tese P-S teve sobre os processos de industrialização dos países em desenvolvimento, diversos trabalhos se incumbiram de testar empiricamente a tese da deterioração dos termos de troca. Grilli e Yang (1988) confirmam a existência da tese, mas não sua magnitude, utilizando dados de preços de commodities dos anos de 1900 a 1986. O caso brasileiro foi testado por Gonçalvez e Barros (1982) - para o período de 1850 a 1979 -, Kannebley Júnior, Gremaud e Rennó (2001) - para o período de 1850 a 2000 - e Marçal (2006) período de 1850 a 2001. Dentre esses trabalhos, apenas o de Marçal (2006) rejeita a hipótese de existência de deterioração dos termos de troca no Brasil no período de análise proposto, os demais a confirmam.

Como apresentado, a análise do papel dos termos de troca sobre a economia brasileira esteve voltada à discussão da existência ou não da deterioração dos termos de troca e seu papel no desenvolvimento industrial. Não há evidências empíricas sobre a real influência dos termos de troca sobre os diversos setores da indústria brasileira. Nesse sentido, o presente trabalho pretende contribuir com a literatura preenchendo essa lacuna.

Os trabalhos empíricos até então realizados buscaram identificar somente os impactos da volatilidade da taxa de câmbio sobre os setores agregados segundo 
os níveis de intensidade tecnológica. ${ }^{2}$ Dentre os trabalhos que utilizaram essa classificação estão os de Nakabashi, Cruz e Scatolin (2008) e Amitrano et al. (2011). Ambos procuram identificar os efeitos do comportamento da taxa de câmbio sobre a pauta exportadora, a estrutura produtiva industrial e a produtividade dos segmentos industriais classificados de acordo com a intensidade tecnológica.

Nakabashi, Cruz e Scatolin (2008) concluem que as atividades econômicas intensivas em trabalho sofrem relativamente mais que os outros segmentos devido à política cambial: a relação de causalidade vai da apreciação cambial para um pior desempenho relativo de suas exportações. Assim, o crescimento da demanda mundial por commodities agrícolas estaria gerando um efeito crowding-out das exportações do segmento industrial intensivo em trabalho através do processo de apreciação cambial. Com relação aos demais segmentos, os autores chegaram ao resultado de que a apreciação do câmbio não teve muita relevância na determinação da participação relativa das exportações de cada um deles, exceto por uma pequena melhora relativa das exportações dos segmentos baseados em diferenciação (taxa de câmbio) e em ciência (taxa de câmbio defasada). Amitrano et al. (2011) constatam que, nos grupos denominados de baixa e alta intensidade tecnológica, a influência do câmbio pareceu mais evidente, notadamente no primeiro caso, ao passo que os produtos classificados como de média-baixa e média-alta tecnologia apresentaram associações menos conclusivas.

\section{Metodologia}

A análise dos efeitos das variações dos termos de troca sobre variáveis setoriais é realizada por meio de um modelo de EGC dinâmico, cuja especificação teórica, calibragem e estratégias de simulação são descritas nas próximas três subseções.

\subsection{Especificação Teórica do Modelo}

O modelo utilizado neste trabalho é uma expansão do modelo Orani-G desenvolvida por Horridge (2006). O seu desenvolvimento para o caso brasileiro deu origem ao Orani-GBR, que, com a implementação de dinâmica recursiva, permite a análise de equilíbrio geral ao longo do tempo. A implementação do módulo dinâmico segue a abordagem proposta por Dixon e Rimmer (2002), possibilitando a análise de acumulação de capital entre períodos através da expectativa da taxa

2 A classificação segundo o nível de intensidade tecnológica é proposta pela Organização para a Cooperação e Desenvolvimento Econômico (OCDE) e corresponde a uma espécie de agregação dos setores econômicos em quartis, de acordo com dados objetivos coletados sobre as empresas que os compõem. 
de retorno do setor. O emprego também apresenta um mecanismo de ajuste temporal envolvendo variáveis como salário real, nível de emprego atual e nível de emprego tendencial.

A especificação teórica do modelo é amplamente detalhada por Horridge (2006) e Dixon e Rimmer (2002), de modo que aqui apresenta-se sua estrutura de forma sintética para os principais agentes econômicos do modelo (firmas, famílias, investidores, governo e exportadores). O comportamento de otimização dos agentes considera que a economia funciona em regime de preços flexíveis no mercado de bens e preços (salários) rígidos no mercado de trabalho a curto prazo. No longo prazo, os salários são considerados flexíveis e o emprego converge para o nível tendencial. Os setores produtivos minimizam os custos de produção sujeitos a uma tecnologia de retornos constantes de escala, em que a combinação de insumos intermediários e fator primário (agregado) é determinada por coeficientes fixos (função Leontief). Na composição dos insumos, há substituição via preços entre produto doméstico e importado, por meio de funções de elasticidade de substituição constante (CES). Na composição do fator primário também há substituição via preço entre capital e trabalho por funções CES. A Figura 1 apresenta a estrutura da função de produção. Embora todos os setores apresentem a mesma especificação teórica, os efeitos substituição via preços se diferenciam de acordo com a composição doméstico/importado dos insumos do setor (presente na base de dados).

Figura1 - Estrutura da função de produção do modelo Orani-GBR

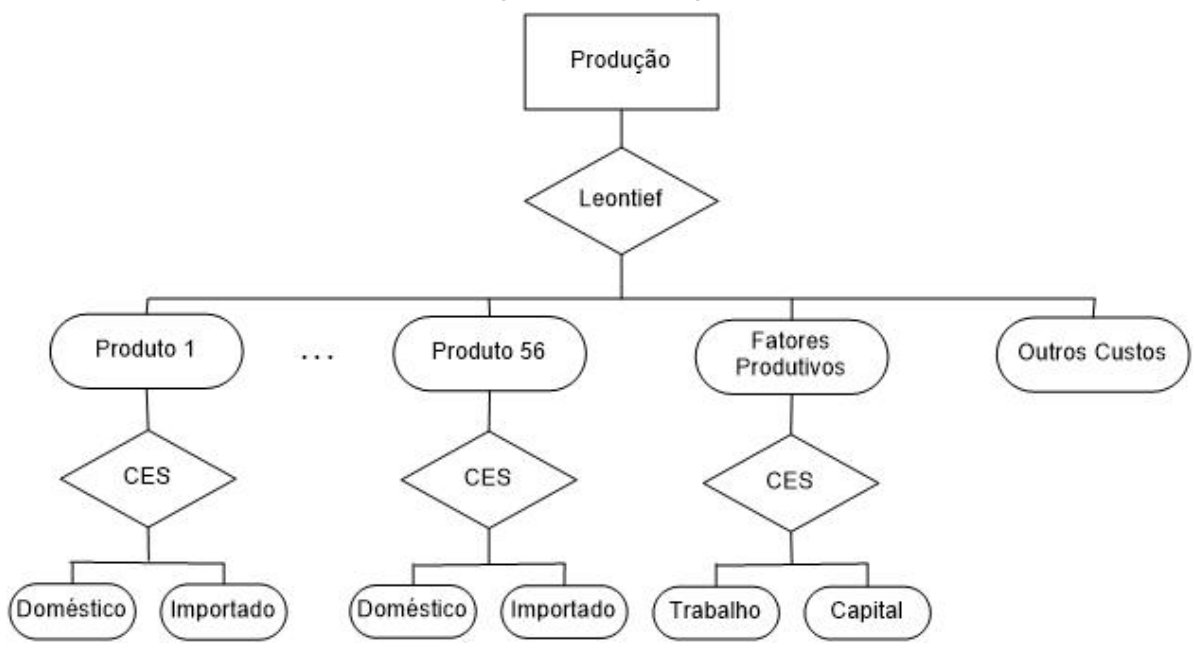

Fonte: Elaboração própria. 
No modelo, há uma família representativa que consome bens domésticos e bens importados. A escolha entre domésticos e importados (de outros países) é realizada por uma especificação CES (hipótese de Armington). O tratamento da demanda das famílias é baseado em um sistema combinado de preferências CES/Klein-Rubin. Assim, a utilidade derivada do consumo é maximizada segundo essa função de utilidade. Essa especificação dá origem ao sistema linear de gastos (LES), no qual a participação do gasto acima do nível de subsistência, para cada bem, representa uma proporção constante do gasto total de subsistência de cada família.

O consumo do governo é exógeno. A demanda por exportações é definida como uma função decrescente dos custos domésticos de produção e crescente da renda internacional, adotando-se a hipótese de país pequeno no comércio internacional. Por sua vez, a variação de estoques acompanha o nível de produção dos setores.

O modelo opera com equilíbrio de mercado para todos os bens, tanto domésticos quanto importados, assim como no mercado de fatores (capital e trabalho). Os preços de compra para cada um dos agentes econômicos são a soma dos valores básicos e dos impostos sobre vendas (diretos e indiretos) e margens (de comércio e transporte). Impostos sobre vendas são tratados como taxas ad valorem sobre os fluxos básicos. As demandas por margens (transporte e comércio) são proporcionais aos fluxos de aquisição dos bens aos quais as margens estão conectadas. A estrutura de produção considera que cada indústria pode produzir vários produtos (produção secundária), utilizando os insumos (domésticos e importados) e os fatores produtivos (capital e trabalho).

O investimento e o estoque de capital seguem mecanismos de acumulação e de deslocamento intersetorial a partir de regras pré-estabelecidas, associadas à taxa de depreciação e retorno. Conforme Dixon e Rimmer (1998), em cada ano de simulação, assumem-se que as taxas de crescimento do capital da indústria $j$ (e dessa forma, os níveis de investimento) são determinadas pela disposição dos investidores em fornecer fundos à indústria $j$ frente aos aumentos na taxa de retorno esperada em j. Os possíveis distúrbios da taxa de retorno são eliminados gradualmente ao longo do tempo. Em outras palavras, admite-se que o crescimento do capital de j no ano $t$ é limitado pela expectativa de risco do investidor e dos custos de instalação crescentes (via seus efeitos nos custos unitários da construção e outras indústrias fornecedoras de capital). Basicamente, a taxa de crescimento do capital na indústria j no ano $t$ só será maior que sua taxa normal (estado estacionário do crescimento de capital) à medida que a taxa de retorno esperada pelos investidores for superior à taxa de retorno normal (DIXON; RIMMER, 1998).

É importante salientar que na modelagem de EGC com dinâmica recursiva há um amortecimento das respostas do investimento, uma vez que o custo de uma 
unidade extra de capital instalado na indústria $j$ no ano $t$ é uma função crescente do investimento da indústria $j$ durante o ano $t$. Na maioria das firmas, os custos por unidade de serviços de construção e outros insumos para criação de capital são fracamente dependentes das variações no próprio investimento da firma (DIXON; RIMMER, 2002).

O mercado de trabalho apresenta um elemento de ajuste intertemporal. Ele envolve basicamente três variáveis: salário real, emprego atual e emprego tendencial. No seu mecanismo de ajuste, quando o nível de emprego em $t+1$ exceder o emprego tendencial da economia, o salário real aumenta. Dessa maneira, visto que existe uma relação negativa entre emprego e salário real no mercado de trabalho, o aumento no salário real no período anterior tende a elevar os custos de produção, levando a um ajustamento do nível de emprego em períodos posteriores até convergir para o nível tendencial. Assume-se, dessa forma, que a demanda por trabalho determina a quantidade de trabalhadores utilizados na produção e que os salários reais são rígidos no curto prazo, mas flexíveis no longo prazo.

A formalização matemática das principais equações do modelo, como também do mecanismo de acumulação de capital físico e do mercado de trabalho, é apresentada resumidamente no Apêndice A.

\subsection{Calibragem da Base de Dados}

O modelo foi calibrado inicialmente com dados obtidos do sistema de contas nacionais do IBGE de 2007 (IBGE, 2016). Para se estimar os fluxos monetários a preços básicos e a desagregação das margens e tributos que alimentam a matriz de absorção do modelo (Figura 2), foi empregada a mesma metodologia proposta por Guilhoto et al. (2002). A estrutura da base de dados do modelo é multisetorial e compreende 56 setores, 56 produtos e 2 fatores produtivos (capital e trabalho). O fator trabalho é ainda desagregado em 8 classes de renda para viabilizar análises de efeitos distributivos, sendo elas: até $1 / 2$ salário mínimo (SM); de $1 / 2$ SM até 1 SM; de 1 SM até 2 SM; de 2 SM até 3 SM; de 3 SM até 5 SM; de 5 SM até 10 SM; de 10 SM até 20 SM; mais de 20 SM.

Os fluxos monetários da matriz de absorção permitem deduzir as relações estruturais específicas dos setores produtivos tais como coeficientes técnicos de insumos segundo sua origem (doméstica e importada), requerimentos de fatores produtivos e carga de tributação indireta. Os parâmetros condizentes com a especificação teórica envolvem elasticidades de substituição entre fatores primários, elasticidades de Armington, elasticidades-preço das exportações e elasticidade dos gastos familiares. Para as elasticidades de substituição, utilizou-se o valor usual de 0,5, mantendo-se o mesmo padrão de calibragem usado por Horridge (2006). As elasticidades de Armington foram definidas com base nos valores estimados 
por Tourinho, Kume e Pedroso (2003) e as elasticidades da função consumo das famílias foram obtidas de Almeida (2011), sendo ambas específicas para cada bem. Já as elasticidades-preço das exportações foram calibradas com base no estudo de Souza e Luporini (2011), possuindo valor de 0,685 para os bens agropecuários e da indústria extrativa e valor de 1,786 para os demais bens de exportação. Para todas as elasticidades usadas na calibragem da base de dados, foram realizadas análises de sensibilidade sistemáticas para a robustez das simulações, as quais indicaram que mudanças nos valores das elasticidades não influenciaram nos resultados das simulações. ${ }^{3}$

Figura 2 - Estrutura da matriz de absorção do modelo Orani-GBR

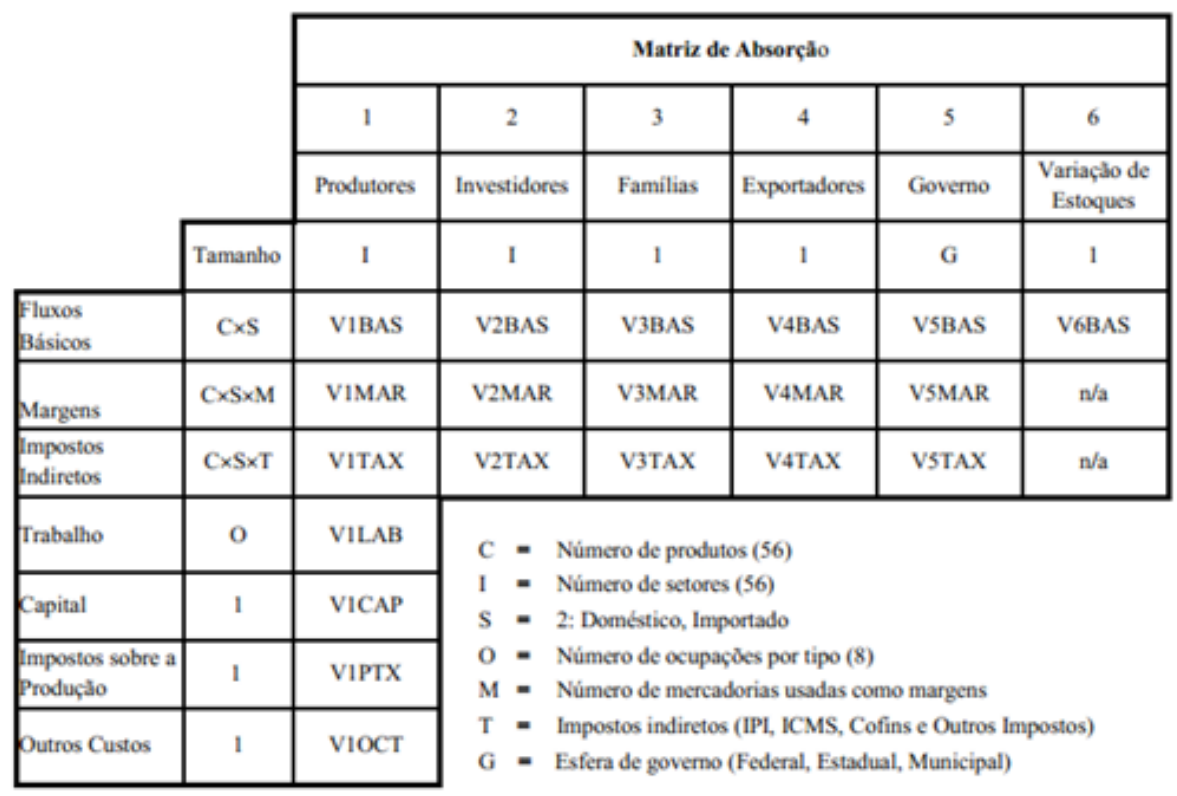

Fonte: Elaboração própria a partir de Horridge (2006).

\subsection{Estratégia de Fechamento e Simulação}

Antes de realizar a simulação dos impactos das variações dos termos de troca na economia brasileira para o período de 2008 a 2014, é preciso definir o fechamento do modelo. O fechamento é a determinação dos conjuntos de variáveis endógenas e exógenas das simulações realizadas. Nesse caso, representa as hipóteses sobre o funcionamento da economia e seus ajustamentos a choques (políticas). O modelo é dinâmico e permite a acumulação do capital ao longo do tempo e

3 O procedimento usado foi similar ao empregado no estudo de Domingues e Haddad (2005). 
ajustes no mercado de trabalho. Assume-se que o consumo das famílias segue a renda nominal nacional e que o gasto do governo possui uma relação constante com o gasto das famílias, representando uma regularidade empírica de longo prazo. Além disso, a participação do saldo da balança comercial nominal sobre o PIB nominal é determinada endogenamente. O modelo trabalha com preços relativos e a variável de preços escolhida como numerário foi o índice de preços ao consumidor (IPC). Também tem-se o crescimento populacional e o índice de preços dos importados como variáveis exógenas.

Para o fechamento de simulação histórica, que visa reproduzir o cenário macroeconômico observado do período, assume-se que os principais agregados macroeconômicos (PIB real, investimento agregado, consumo das famílias, gastos do governo, emprego agregado, termos de troca e volume agregado de exportações) são exógenos. Em contrapartida, define-se como endógenas as variáveis de deslocamento para a taxa de retorno bruta, o salário nacional, o deslocamento da demanda do governo, o deslocamento das exportações, assim como a variável de mudança tecnológica dos fatores de produção e a substituição entre bens importados e domésticos. Dessa forma, foi possível construir um conjunto de choques macroeconômicos agregados para essas variáveis exógenas que replicam seu comportamento observado no período de 2008 a 2014. Portanto, a simulação histórica garante que os resultados sejam consistentes com a evolução real das variáveis macroeconômicas em conformidade com as informações estatísticas existentes.

Dessa forma, a simulação considerou os dados disponíveis para as variações percentuais do consumo das famílias, dos gastos do governo, dos investimentos (variação da formação bruta de capital fixo), das exportações agregadas (volume), da taxa de ocupação (emprego), do IPC e do PIB. As variações anuais das variáveis macroeconômicas foram calculadas com os dados de séries históricas do IBGE e são apresentadas na Tabela 1. 
Tabela 1 - Variação percentual anual das variáveis exógenas na simulação

\begin{tabular}{lccccccc}
\hline Variável & $\mathbf{2 0 0 8}$ & $\mathbf{2 0 0 9}$ & $\mathbf{2 0 1 0}$ & $\mathbf{2 0 1 1}$ & $\mathbf{2 0 1 2}$ & $\mathbf{2 0 1 3}$ & $\mathbf{2 0 1 4}$ \\
\hline PIB real & 5,00 & $-0,20$ & 7,60 & 3,90 & 1,80 & 2,70 & 0,10 \\
Consumo das famílias & 5,46 & 4,46 & 6,63 & 4,74 & 3,50 & 3,48 & 1,32 \\
Gastos do governo & 3,17 & 3,11 & 4,23 & 1,93 & 3,33 & 1,89 & 1,17 \\
Investimentos & 12,69 & $-1,87$ & 17,79 & 6,59 & $-0,60$ & 6,10 & $-4,40$ \\
Exportações (volume) & $-2,46$ & $-10,75$ & 9,50 & 2,92 & $-0,33$ & 3,05 & $-1,80$ \\
Emprego agregado & 2,99 & 0,90 & 0,73 & 0,73 & 1,72 & 0,19 & 2,75 \\
Crescimento populacional & 1,05 & 0,99 & 0,93 & 0,87 & 0,82 & 0,77 & 0,73 \\
Termos de troca & 3,72 & $-2,56$ & 16,00 & 7,80 & $-5,84$ & $-2,04$ & $-3,38$ \\
IPC & 6,07 & 3,95 & 6,24 & 6,36 & 5,74 & 5,63 & 6,87 \\
\hline
\end{tabular}

Fonte: Fundação Centro de Estudos do Comércio Exterior (2016) e Instituto Brasileiro de Geografia e Estatística (2016).

Com relação aos termos de troca, suas variações foram calculadas por meio dos dados disponibilizados pela Fundação Centro de Estudos do Comércio Exterior (2016). O índice de termos de troca da Funcex (2016) é elaborado a partir dos índices de preços e de quantum das exportações e importações, sendo construído para o conjunto da economia. Desse modo, na simulação a variação dos termos de troca apresentada na Tabela 1 é válida para todos os 56 setores de atividade econômica presentes no modelo.

A observação das variações percentuais dos termos de troca permite identificar que no período de análise (2008 a 2014) ocorreram movimentos distintos nessa variável. De 2008 a 2011 (com excessão de 2009) ocorreu uma valorização dos termos de troca impulsionada principalmente pelos elevados e crescentes preços das commodities no mercado internacional e pela queda no preço dos bens manufaturados. Por ser um exportador de commodities, o Brasil se beneficiou com esse cenário, melhorando seus termos de troca. Porém, a partir de 2012, observou-se uma deterioração dos termos de troca, a qual foi motivada pela desaceleração da economia chinesa e pela queda no preço das commodities no mercado internacional. A simulação realizada permite visualizar os efeitos desses dois movimemtos contrários dos termos de troca sobre os setores industriais.

Com a simulação histórica, são encontrados os valores das mudanças tecnológicas que ocorreram na economia brasileira nesse período. A partir disso, é realizada uma simulação de decomposição para se isolar o efeito das mudanças nos termos de troca. Nessa projeção, as variáveis PIB, emprego agregado e consumo voltam a ser endógenas e um conjunto de choques é aplicado nas variáveis tecnológicas com o valor encontrado na primeira simulação. Esse procedimento gera um resultado macroeconômico igual ao cenário histórico, contudo, permite 
isolar os impactos das variações dos termos de troca nos principais indicadores agregados.

\section{Resultados e Discussões}

Com o objetivo de melhor compreender os efeitos das variações dos termos de troca sobre as variáveis agregadas e sobre os setores de atividade industriais, os resultados da trajetória histórica de algumas variáveis foram divididos em dois grupos. O primeiro compreende os resultados dos anos 2008 a 2011, período em que ocorreu valorização dos termos de troca (com exceção do ano 2009, afetado pela crise econômica mundial), e o segundo compreende os anos 2012 a 2014, período no qual se observou a desvalorização dos termos de troca.

A apresentação dos resultados também se divide entre efeitos totais e efeitos dos termos de troca, pois a simulação engloba os efeitos de todos os indicadores da economia, além dos efeitos específicos dos termos de troca.

\subsection{Resultados Agregados}

As variações dos termos de troca afetam as variáveis macroecônomicas através de canais de transmissão, que podem ser diretos ou indiretos.

O principal canal direto é o efeito preço das exportações de commodities. Um aumento nos termos de troca significa que os preços dos bens de exportação estão relativamente maiores que os preços dos bens importados. Esse aumento deixa os bens nacionais mais caros no exterior, reduz sua competitividade e leva a uma queda no quantum exportado. Porém, o aumento dos preços dos bens de exportação leva a uma maior rentabilidade, fato que tenderia a aumentar o quantum de exportado.

Os resultados da simulação apresentados na Tabela 2 indicam que o primeiro efeito prevaleceu na economia brasileira no período analisado. $\mathrm{O}$ aumento acumulado de $24,96 \%$ nos termos de troca, ocorrido no período compreendido entre 2008 e 2011, impactou o volume de exportações em -40,39\%, resultado que contribuiu significativamente para o efeito total negativo do período. Situação contrária ocorreu no período de 2012 a 2014: a queda acumulada de 11,26\% nos termos de troca levou a aumento de $20,46 \%$ no volume de exportações.

As variações dos termos de troca também exerceram efeitos consideráveis sobre o nível de importações. Esses efeitos também resultam do efeito preço, os bens importados se tornaram relativamente mais baratos em relação aos domésticos e isso contribuiu para o aumento do volume de importações. É importante ressaltar o papel da renda interna na determinação da variação total no volume das importações. Em um estudo sobre taxas de câmbio e balança comercial, 
Meyer, Paula e Pires (2011) afirmam que, até 2008, as importações tiveram seu crescimento determinado fundamentalmente pelo aumento da renda doméstica em função da alta elasticidade-renda das importações da economia brasileira. Essa constatação pode ser estendida para o período de 2008 a 2014, principalmente até 2011, período em que o país experimentou elevado crescimento do PIB, guiado principalmente pelo consumo e investimento. ${ }^{4}$

A taxa de câmbio é um dos canais indiretos de transmissão do efeito das mudanças nos termos de troca: quando há aumento (redução) dos termos de troca, o câmbio se aprecia (deprecia). A depreciação do câmbio pode apresentar diversos impactos diretos e indiretos sobre a atividade econômica, dentre os mais relevantes está o impacto sobre a demanda agregada, que é afetada pela mudança nos preços relativos: há aumento das exportações e redução das importações. Pelo lado da oferta, a produção é negativamente afetada pelo reajuste dos salários, devido ao aumento dos preços dos produtos finais e pela elevação dos preços dos insumos e bens de capital importados (FOCHEZATTO; SOUZA, 2000).

Os efeitos das variações dos termos de troca sobre o PIB ocorrem pelos canais diretos (efeito preço das exportações) e indiretos (efeitos câmbio). Os resultados obtidos na simulação apontaram que o aumento dos termos de troca exerceu impacto negativo sobre o PIB no período de 2008 a 2011 . Entretanto, esse impacto não foi significativo, visto que a variação total do PIB no período foi positiva. Entre 2012 e 2014, as variações dos termos de troca provocaram efeitos positivos sobre o PIB e foram um dos fatores que contribuíram para o crescimento do período.

Para se compreender esses resultados, é necessário observar os movimentos dos componentes do PIB no período de análise. Os anos de 2008 a 2011 foram marcados pelo estímulo à demanda agregada com significativos aumentos do consumo das famílias e dos gastos do governo. Assim, o efeito negativo dos termos de troca sobre o PIB nesses anos foi pequeno frente aos efeitos maiores (positivos) do consumo interno. Por outro lado, entre 2012 e 2014 se verificou um enfraquecimento da dinâmica do mercado interno, o consumo das famílias e do governo cresceram a taxas inferiores a dos anos anteriores. Nesse período, o efeito dos termos de troca sobre o PIB é positivo e tem o mesmo sentido do efeito total, ou seja, de 2012 a 2014, as variações dos termos de troca tiveram uma importância maior no resultado do PIB em comparação ao período de 2008 a 2011.

Exceto em 2009, quando o país sofreu uma retração econômica por causa da crise financeira internacional. 
Tabela 2 - Variações acumuladas (\%) das variáveis macroeconômicas

\begin{tabular}{lcccc}
\hline & \multicolumn{2}{c}{ 2008-2011 } & \multicolumn{2}{c}{ 2012-2014 } \\
\hline Variável & Efeito total & $\begin{array}{c}\text { Efeito termos } \\
\text { de troca }\end{array}$ & Efeito total & $\begin{array}{c}\text { Efeito termos } \\
\text { de troca }\end{array}$ \\
\hline PIB real & 16,13 & $-10,75$ & 4,90 & 5,40 \\
Consumo das famílias & 21,11 & $-6,90$ & 8,48 & 3,41 \\
Exportações (volume) & $-1,91$ & $-40,39$ & 2,04 & 20,46 \\
Importações (volume) & 44,88 & 15,40 & 16,14 & $-7,90$ \\
Emprego agregado & 5,12 & $-5,63$ & 4,87 & 2,83 \\
\hline
\end{tabular}

Fonte: Elaboração própria a partir dos resultados da simulação.

A respeito do nível de emprego, a Tabela 3 mostra o efeito das variações dos termos de troca sobre o nível de emprego desagregado por classes salariais. No período de 2008 a 2011, o efeito das variações dos termos de troca sobre o nível de emprego foi negativo em todas as classes salariais. Entretanto, o efeito total, que agrega todo o cenário macroeconômico, foi positivo. Essa constatação sugere que não foram as mudanças nos termos de troca o principal determinante do nível de emprego no período. Já nos anos de 2012 a 2014, o efeito termos de troca não apenas teve o mesmo sinal positivo do efeito total, como foi responsável por grande parcela do crescimento positivo do período.

Tabela 3 - Variações acumuladas (\%) do nível de emprego segundo classes salariais

\begin{tabular}{lcccc}
\hline & \multicolumn{2}{c}{ 2008-2011 } & \multicolumn{2}{c}{ 2012-2014 } \\
\hline Classe salarial & Efeito total & $\begin{array}{c}\text { Efeito termos } \\
\text { de troca }\end{array}$ & Efeito total & $\begin{array}{c}\text { Efeito termos } \\
\text { de troca }\end{array}$ \\
\hline Até 1/2 SM & 2,34 & $-8,36$ & 8,99 & 4,27 \\
1/2 a 1 SM & 3,10 & $-7,26$ & 6,33 & 3,67 \\
1 a 2 SM & 4,07 & $-7,73$ & 5,00 & 3,76 \\
2 a 3 SM & 4,17 & $-7,34$ & 5,39 & 3,58 \\
3 a 5 SM & 4,66 & $-5,41$ & 3,88 & 2,65 \\
5 a 10 SM & 4,89 & $-5,10$ & 5,54 & 2,59 \\
10 a 20 SM & 7,70 & $-3,77$ & 2,95 & 1,97 \\
Mais de 20 SM & 5,95 & $-4,17$ & 6,28 & 2,29 \\
\hline
\end{tabular}

Fonte: Elaboração própria a partir dos resultados da simulação.

O efeito dos termos de troca, e consequentemente da taxa de câmbio real, sobre o nível de emprego é resultado do efeito dos mesmos sobre o salário real. Por sua vez, o efeito sobre o salário real se dá através do nível de preços, uma de- 
preciação (apreciação) cambial aumenta (diminui) os preços dos bens tradables e aumenta (diminui) o custo dos bens non-tradables gerando aumento (redução) no nível geral de preços e reduzindo (aumentando) o salário real. ${ }^{5}$ Por afetar diretamente o salário real, a taxa de câmbio real impacta o grau de especialização produtiva da economia, uma apreciação do câmbio real, via de regra, causa aumento do salário real, aumentando, assim, o custo de produção no país relativamente ao custo de outros países (OREIRO; LEMOS; SILVA, 2007).

\subsection{Resultados Setoriais}

Como os termos de troca podem afetar a demanda e a oferta agregadas, a análise de variáveis como demanda, produção e emprego setoriais são elementos chaves na identificação de como as variações dos termos de trocam influenciaram nos resultados dos setores industriais.

O modelo EGC é uma ferramenta adequada para identificar como os diversos setores são afetados ao longo do tempo por meio da análise da decomposição dos resultados sobre a variação da produção. Essa decomposição mostra a magnitude relativa de três efeitos sobre a produção: o efeito do mercado local (aumento no uso doméstico do bem, seja produzido internamente ou importado), o efeito das exportações (aumento das exportações do setor) e o efeito de participação doméstica (deslocamento do uso de bens importados para bens domésticos).

$\mathrm{Na}$ Tabela 4 são apresentados os 20 setores industriais que apresentaram os maiores impactos no nível de atividade em razão da valorização dos termos de troca no período de 2008 a 2011. Nota-se que a última coluna mostra a variação percentual acumulada no período, dado o cenário macroeconômico. Nesse período, com exceção de 2009, a economia brasileira apresentou elevado crescimento econômico e, por essa razão, a maioria dos setores apresentaram significativo crescimento. Contudo, quando considera-se apenas o efeito da valorização dos termos de troca, pode-se observar que impactou de forma negativa na produção industrial (com exceção do setor de cimento). Esses resultados sugerem que, no período em questão, as oscilações dos termos de troca não exerceram influência significativa sobre as variações setorias do nível de atividade econômica. Outros fatores, como o aumento do consumo interno, foram determinantes para os resultados totais positivios alcançados no período.

5 Para mais detalhes do efeito do câmbio sobre os salários reais, ver Gala e Libanio (2008). 
Tabela 4 - Decomposição dos efeitos das mudanças dos termos de troca sobre o nível de atividade dos 20 setores industriais mais afetados pela valorização dos termos de troca do período 2008 a 2011 (variação \% acumulada)

\begin{tabular}{|c|c|c|c|c|c|}
\hline \multicolumn{6}{|c|}{ Mais afetados: valorização nos termos de troca de 2008 a 2011} \\
\hline Setor & $\begin{array}{c}\text { Mercado } \\
\text { local }\end{array}$ & $\begin{array}{c}\text { Participação } \\
\text { doméstica }\end{array}$ & Exportações & $\begin{array}{c}\text { Variação } \\
\% \text { total } \\
\text { (efeito } \\
\text { termos } \\
\text { de troca) }\end{array}$ & $\begin{array}{c}\text { Variação } \\
\text { \% total } \\
\text { (cenário } \\
\text { macro) }\end{array}$ \\
\hline Fumo & $-8,89$ & $-7,42$ & $-12,90$ & $-29,22$ & $-23,97$ \\
\hline $\begin{array}{l}\text { Alimentos e } \\
\text { bebidas }\end{array}$ & $-10,21$ & $-1,29$ & $-5,17$ & $-16,68$ & $-0,98$ \\
\hline Metais não ferrosos & $-0,38$ & $-3,84$ & $-9,90$ & $-14,11$ & 4,86 \\
\hline Peças e acessórios & $-8,10$ & $-0,52$ & $-4,84$ & $-13,46$ & 10,16 \\
\hline $\begin{array}{l}\text { Outros de } \\
\text { transporte }\end{array}$ & $-0,22$ & $-0,68$ & $-12,15$ & $-13,05$ & 5,33 \\
\hline Caminhões & $-1,94$ & $-1,09$ & $-9,95$ & $-12,98$ & 10,99 \\
\hline Vestuário & $-11,43$ & $-0,80$ & $-0,36$ & $-12,57$ & 4,63 \\
\hline Móveis & $-8,71$ & $-1,40$ & $-1,57$ & $-11,68$ & 7,35 \\
\hline Químicos & $-0,20$ & $-8,53$ & $-2,84$ & $-11,58$ & 13,78 \\
\hline Resina e elastano & 0,28 & $-7,27$ & $-4,15$ & $-11,13$ & 14,32 \\
\hline Têxteis & $-5,03$ & $-3,63$ & $-2,00$ & $-10,66$ & 10,34 \\
\hline $\begin{array}{l}\text { Máquinas e } \\
\text { equipamentos }\end{array}$ & $-2,50$ & $-2,79$ & $-4,96$ & $-10,26$ & 16,21 \\
\hline Couro e calçados & $-1,56$ & $-0,12$ & $-8,14$ & $-9,83$ & 6,03 \\
\hline Outros químicos & 1,80 & $-7,53$ & $-4,03$ & $-9,77$ & 15,31 \\
\hline Aço & $-1,98$ & $-0,52$ & $-6,08$ & $-8,58$ & 13,90 \\
\hline Outros da extrativa & $-0,66$ & $-5,54$ & $-2,16$ & $-8,36$ & 15,54 \\
\hline Metal & $-1,37$ & $-3,98$ & $-1,23$ & $-6,58$ & 21,25 \\
\hline Madeira & 2,20 & $-0,48$ & $-7,45$ & $-5,72$ & 17,57 \\
\hline Borracha e plástico & $-1,39$ & $-2,36$ & $-2,05$ & $-5,81$ & 22,64 \\
\hline Cimento & 7,77 & $-0,31$ & $-0,55$ & 6,91 & 41,68 \\
\hline
\end{tabular}

Fonte: Elaboração própria a partir dos resultados da simulação.

Em alguns setores, tais como fumo, metais não ferrosos, outros de transporte, caminhões, couro e calçados e madeira, o efeito negativo dos termos de troca se deve principalmente à queda das exportações. Nos demais setores, a variação negativa é resultado da queda na produção para atender o mercado local e pela substituição de bens domésticos por importados. 
Como uma valorização dos termos de troca geralmente é acompanhada por uma apreciação da taxa de câmbio, observar como esta afeta os setores industriais é um dos meios de compreender como as variações dos termos de troca afetam as atividades industriais. De acordo com Lacerda (2013), as empresas se adaptam a situações de câmbio apreciado, aumentando a importação de componentes e peças, o que as ajuda a reduzir custos e a manter a competitividade. Embora seja uma adaptação individual das empresas, do ponto de vista da estrutura produtiva do país trata-se de um processo de substituição do produto local pelo importado, desestimulando a geração de valor agregado local. Além disso, a apreciação cambial pode interferir nas margens de lucro setoriais, pois interfere nos preços de venda. Gala e Mori (2009) argumentam que a apreciação cambial representa uma queda imediata e intensa de preços de vendas e margens de lucro em toda cadeia que trabalha com preços internacionais, especialmente nos setores que não têm poder de mercado.

Entre 2012 e 2014 ocorre o oposto (ver Tabela 5). A desvalorização dos termos de troca impactou positivamente a produção na maioria dos setores. As causas desse aumento se diferenciam entre os setores: nos exportadores (fumo, metais não ferrosos, caminhões, outros transportes, couro e calçados e aço), o aumento da produção deveu-se ao aumento das exportações; por outro lado, setores voltados a atender a demanda interna, tais como alimentos e bebidas e vestuário, o aumento da produção deveu-se ao mercado local. Assim como nos resultados agregados, entre 2012 e 2014 o efeito dos termos de troca na maioria dos setores foi positivo (com excessão do setor de fumo), contribuindo para a variação positiva total no nível de atividade setorial. 
Tabela 5 - Decomposição dos efeitos das mudanças dos termos de troca sobre o nível de atividade dos 20 setores industriais mais afetados pela desvalorização dos termos de troca do período 2012 a 2014 (variação \% acumulada)

\begin{tabular}{|c|c|c|c|c|c|}
\hline \multicolumn{6}{|c|}{ Mais afetados: desvalorização dos termos de troca de 2012 a 2014} \\
\hline Setor & $\begin{array}{l}\text { Mercado } \\
\text { local }\end{array}$ & $\begin{array}{l}\text { Participação } \\
\text { doméstica }\end{array}$ & Exportações & $\begin{array}{c}\text { Variação } \\
\% \text { total } \\
\text { (efeito } \\
\text { termos } \\
\text { de troca) }\end{array}$ & $\begin{array}{c}\text { Variação } \\
\text { \% total } \\
\text { (cenário } \\
\text { macro) }\end{array}$ \\
\hline Fumo & 4,13 & 4,54 & 7,25 & 15,93 & $-10,32$ \\
\hline Alimentos e bebidas & 5,04 & 0,81 & 2,11 & 7,96 & 2,24 \\
\hline Metais não ferrosos & $-0,11$ & 2,28 & 4,19 & 6,36 & 16,79 \\
\hline Caminhões & 1,53 & 0,92 & 3,59 & 6,05 & 2,59 \\
\hline Químicos & 0,06 & 4,86 & 1,13 & 6,03 & 26,43 \\
\hline Vestuário & 5,41 & 0,45 & 0,16 & 6,01 & $-4,32$ \\
\hline Peças e acessórios & 3,48 & 0,27 & 1,92 & 5,65 & 18,52 \\
\hline Têxteis & 2,62 & 2,12 & 0,88 & 5,62 & 10,50 \\
\hline Móveis & 3,89 & 0,82 & 0,69 & 5,41 & 0,98 \\
\hline Resina e elastano & $-0,37$ & 4,15 & 1,59 & 5,37 & 25,92 \\
\hline $\begin{array}{l}\text { Outros de } \\
\text { transporte }\end{array}$ & 0,00 & 0,37 & 4,97 & 5,34 & 10,76 \\
\hline Outros químicos & $-0,98$ & 4,30 & 1,60 & 4,92 & 26,76 \\
\hline $\begin{array}{l}\text { Máquinas e } \\
\text { equipamentos }\end{array}$ & 1,18 & 1,57 & 1,93 & 4,69 & 7,88 \\
\hline Couro e calçados & 1,25 & 0,06 & 3,35 & 4,67 & 11,40 \\
\hline Outros da extrativa & 0,02 & 3,16 & 1,00 & 4,19 & 24,36 \\
\hline Metal & 0,40 & 2,50 & 0,48 & 3,40 & 18,12 \\
\hline Aço & 0,60 & 0,29 & 2,48 & 3,37 & 19,73 \\
\hline Borracha e plástico & 0,48 & 1,24 & 0,77 & 2,49 & 22,64 \\
\hline Perfumaria & 1,14 & 0,82 & 0,45 & 2,40 & 8,78 \\
\hline Cimento & $-3,82$ & 0,15 & 0,19 & $-3,48$ & 20,14 \\
\hline
\end{tabular}

Fonte: Elaboração própria a partir dos resultados da simulação.

Os setores com as maiores variações negativas na produção entre 2008 e $2011 \mathrm{em}$ virtude das mudanças dos termos de troca são os mesmos com as maiores variações negativas no nível de emprego (fumo, alimentos e bebidas, metais não ferrosos, vestuário e químicos). Da mesma forma, são as mesmas atividades que apresentam as maiores variações positivas na produção e nível de emprego setoriais no período entre 2012 e 2014. Isso mostra que nesses setores a sensibi- 
lidade aos termos de troca e ao câmbio é maior. Esse resultado deve-se principalmente à maior abertura desses setores ao comércio, tanto como exportadores quanto importadores de máquinas e equipamentos e, por isso, seus custos de produção são mais impactados nos períodos de apreciação e depreciação cambial. Esse maior custo afeta diretamente o valor adicionado bruto e o nível de emprego dessas atividades.

A decomposição do efeito dos termos de troca sobre a produção evidencia um resultado importante a respeito das oscilações dos termos de troca sobre a produção industrial: a manutenção de termos de troca favoráveis às exportações é uma das condições necessárias para melhorar o desempenho de setores com alto coeficiente de exportações.

Considerando que o efeito total (cenário macroeconômico) sobre a produção e o emprego setoriais depende de todos os indicadores da economia, como investimentos, consumo das famílias e gastos do governo, pode-se afirmar que os efeitos setoriais das variações dos termos de troca foram distintos nos dois cenários econômicos presentes no período de análise. Para a maioria dos setores, no período compreendido entre 2008 e 2011, as variações causadas apenas pela valorização dos termos de troca nas variáveis mencionadas foram negativas, enquanto a variação total foi positiva devido ao crescimento econômico do período. Já no período de 2012 a 2014, as mudanças causadas pelos termos de troca, na maioria dos setores, tiveram a mesma direção da variação total (positiva). Essa constatação sugere que no período em que se verificou a valorização, os termos de troca, apesar de sua influência sobre certos setores, não foi o principal determinante das variações na produção, mas sim o crescimento do mercado local. No período de 2012 a 2014, os termos de troca se mostraram relativamente mais importantes para o crescimento da produção setorial, ainda que o crescimento econômico tenha sido mais baixo nesse período.

\section{Considerações Finais}

Este artigo buscou contribuir para a discussão dos efeitos das variações dos termos de troca nos diversos setores da indústria, analisando um período recente da economia brasileira, de 2008 a 2014. O objetivo principal foi identificar as indústrias mais sensíveis às variações dos termos de troca e verificar os principais impactos de suas oscilações sobre os setores de atividade econômica do Brasil nesse período. A metodologia utilizada foi um modelo EGC dinâmico, o Orani-GBR, calibrado com dados de 2007. Com isso, foi possível realizar uma simulação histórica considerando-se os movimentos observados das principais variáveis macroeconômicas, assim como isolar o impacto das variações observadas dos termos de troca. Dada a grande importância que essas variações exercem sobre a 
indústria e a escassez de estudos sobre a influência dos termos de troca e da taxa de câmbio na atividade industrial, este trabalho se mostra relevante na identificação de como variáveis setoriais de produção e emprego reagem a mudanças nos termos de troca. A análise setorial desagregada, a qual permitiu identificar as indústrias mais sujeitas aos efeitos das oscilações dos termos de troca e do câmbio, é a principal contribuição do presente estudo em relação aos trabalhos empíricos produzidos anteriormente, os quais se concentraram em análises agregadas por nível de intensidade tecnológica.

Entre os resultados encontrados, verificou-se que a valorização dos termos de troca provocou uma redução no nível de emprego na maioria dos setores entre 2008 e 2011 e, aumento entre 2012 e 2014. De maneira geral, os resultados indicaram que os setores mais sensíveis às variações dos termos de troca são as atividades relacionadas às indústrias intensivas em recursos naturais e mão de obra, tais como fumo, alimentos e bebidas e metais não ferrosos.

Observou-se também que as variações na produção industrial ocorreram de maneiras diversas entre os setores. Nos setores com maior viés exportador, a variação da produção se deu para atender a demanda do mercado internacional. Nos demais setores, a produção variou para atender o mercado doméstico e para a substituição entre domésticos e importados. Deve-se notar que os resultados sugeriram que a valorização dos termos de troca no período entre 2008 e 2011 não foi a principal força por trás dos resultados setoriais, que foram muito mais influenciados pelo cenário positivo de crescimento do mercado interno. Contudo, os resultados do período entre 2012 e 2014, em que a economia apresentou um crescimento mais baixo, mostraram que a desvalorização dos termos de troca teve um papel muito mais significativo sobre o desempenho setorial da indústria, embora em um cenário de crescimento mais baixo da economia brasileira.

Os resultados sobre o efeito das oscilações dos termos de troca sobre o PIB sugerem que tais efeitos dependem da dinâmica interna da economia brasileira. No período em que a economia estava aquecida, com altos níveis de consumo e investimentos, os termos de troca tiveram pouco efeito sobre os resultados macroeconômicos. Como foi apresentado, nos resultados para o período de 2008 a 2011, os efeitos dos termos de troca foram negativos, enquanto que o efeito total sobre o PIB foi positivo. Por outro lado, quando a economia estava em menor ritmo de crescimento, os termos de troca passaram a ter maior influência sobre o PIB. Entre 2012 e 2014, o efeito dos termos de troca sobre o PIB foi positivo, assim como o efeito total, indicando que nesse período a influência dos termos de troca pode ter sido relativamente maior.

Essas evidências apontam para o período analisado (2008 a 2014), dois resultados relevantes para a compreensão dos efeitos dos termos de troca sobre a atividade industrial via canal de importação e exportação. O primeiro é que, em 
um regime de forte crescimento econômico orientado pela expansão do consumo interno, a valorização dos termos de troca apresenta um baixo impacto sobre a dinâmica industrial. Nesse caso, a perda de competitividade das exportações decorre de fatores internos, mais especificamente devido ao mecanismo de transmissão do aumento de preços dos bens e do salário real no mercado doméstico sobre o custo de produção dos bens de exportações. O segundo é que a melhora dos termos de troca parece ter um papel mais importante para a dinâmica industrial quando a economia está em um regime de baixo crescimento, no qual a pressão da demanda interna sobre os preços e custos de produção dos bens de exportação é amortecida. Ambos resultados sugerem um paradoxo subjacente ao regime de crescimento da economia brasileira, pelo qual parece ser difícil conciliar um regime de alto crescimento com expansão simultânea dos níveis de consumo interno e externo, porque a elevação do consumo interno tende a provocar pressões sobre os preços e salários, que se transmitem para o custo de produção dos bens exportados. Dessa forma, a sustentação do crescimento industrial a taxas mais elevadas com expansão do consumo interno e externo dependeria necessariamente de incremento no nível de produtividade na indústria brasileira. Esse é um aspecto relevante cuja investigação pode ser aprofundada na agenda de pesquisa futura e pode servir de argumento para futuras políticas de promoção do desenvolvimento da indústria e do comércio internacional.

\section{Referências}

ALMEIDA, A. N. Elasticidades renda e preços: análise do consumo familiar a partir dos dados da POF 2008/2009. São Paulo: Nereus/USP, 2011. (Texto para discussão 04).

AMITRANO, C. R. et al. Taxa de câmbio real e heterogeneidade estrutural na indústria de transformação brasileira: uma avaliação preliminar. Brasília, DF: IPEA, 2011. Disponível em: <http://hdl.handle.net/11058/5352>. Acesso em: 07 jun. 2016.

BRESSER-PEREIRA, L. C. Exchange rate: fix, float, or manage it? São Paulo: Fundação Getúlio Vargas, 2004. (Textos para discussão, n. 135, fev. 2004). Disponível em: < http://hdl. handle.net/10438/1955>. Acesso em: 07 jun. 2016.

BRESSER-PEREIRA, L. C.; MARCONI, N. Existe doença holandesa no Brasil? In: IV Fórum de Economia de São Paulo, 4., 2008, São Paulo. Anais. São Paulo: Fundação Getúlio Vargas, 2008. Disponível em: < http://www.bresserpereira.org.br/papers/2008/08.14.Existe. doen\%C3\%A7a.holandesa.comNelson.Marconi.5.4.08.pdf>. Acesso em: 07 jun. 2016.

DE WET, T. J. The effect of a tax on coal in South Africa: a CGE analysis. 2003. $206 \mathrm{f}$. Tese (PhD Economics) - University of Pretoria, Pretoria, 2003. Disponível em: < http://repository.up.ac. za/handle/2263/25937> . Acesso em: 16 abr. 2016.

DIXON, P.; RIMMER, M. Dynamic general equilibrium modelling for forecasting and policy: a practical guide and documentation of Monash. Amsterdam: North Holland/Elsevier, 2002. 
; $\quad$ Forecasting and policy analysis with a dynamic CGE model of Australia. Clayton, Australia: Monash University, 1998. (CoPS/Impact Working Paper, n. PO-90).

DOMINGUES, E. P.; HADDAD, E. H. Sensitivity analysis in computable general equilibrium models: an application for the regional effects of the Free Trade Area of the Americas (FTAA). Brazilian Review of Econometrics, v. 25, n. 1, p. 115-137, 2005.

FOCHEZATTO, A.; SOUZA, N. D. J. D. Estabilização e reformas estruturais no Brasil após o plano real: uma análise de equilíbrio geral computável. Brasília: IPEA, 2000. Disponível em: <http://hdl.handle.net/11058/5114>. Acesso em: 06 jun. 2016.

FUNDAÇÃO CENTRO DE ESTUDOS DO COMÉRCIO EXTERIOR. Indicadores. Rio de Janeiro, 2016. Disponível em: <http://www.funcexdata.com.br>. Acesso em: 20 abr. 2016.

GALA, P.; LIBANIO, G. Efeitos da apreciação cambial nos salários, lucros, consumo, investimento, poupança e produtividade: uma perspectiva de curto e longo prazo. In: ENCONTRO NACIONAL DE ECONOMIA, 36., 2008, Salvador. Anais. Niterói: ANPEC, 2008. Disponível em :< http://www.anpec.org.br/encontro2008/artigos/200807032223270-. pdf > . Acesso em: 07 jun. 2016.

; MORI, R. Sobre os impactos do nível do câmbio real na formação bruta de capital fixo, no produto potencial e no crescimento. In: MICHEL, R.; CARVALHO, L. (Org.). Crescimento econômico: setor externo e inflação. Brasília, DF: IPEA, p. 87-103, 2009.

GONÇALVES, R.; BARROS, A. C. Tendências dos termos de troca: a tese de Prebisch e a economia brasileira - 1850/1979. Pesquisa e Planejamento Econômico, v. 12, n. 1, p. 109-132, 1982.

GRILLI, E. R.; YANG, M. C. Primary commodity prices, manufactured goods prices, and the terms of trade of developing countries: what the long run shows. The World Bank Economic Review, v. 2, n. 1, 1988.

GUILHOTO, J. J. et al. Nota metodológica: construção da matriz insumo-produto utilizando dados preliminares das contas nacionais. MPRA Paper 54182, University Library of Munich, Germany, 2002. Disponível em: < https://mpra.ub.uni-muenchen.de/54182/1/MPRA_ paper_54182.pdf>. Acesso em: 03 jan. 2016.

HORRIDGE, M. Orani-G: a generic single-country computable general equilibrium model. Melbourne, Australia: Centre of Policy Studies, Victoria University, 2000. (Working Paper, n. OP-93). Disponível em: <http://www.copsmodels.com/elecpapr/op-93.htm>. Acesso em: 04 jan. 2016.

INSTITUTO BRASILEIRO DE GEOGRAFIA E ESTATÍSTICA. Séries históricas e estatísticas. Rio de Janeiro, 2016. Disponível em: <http://seriesestatisticas.ibge.gov.br>. Acesso em: 10 mar. 2016.

Sistema de Contas Nacionais - SCN. Rio de Janeiro, 2016. Disponível em: < https:// www.ibge.gov.br/estatisticas-novoportal/economicas/servicos/9052-sistema-de-contasnacionais-brasil.html? =Ėt=downloads $>$. Acesso em: 10 fev. 2016.

KANNEBLEY JÚNIOR, S.; GREMAUD, A. P.; RENNÓ, R. A. A tendência secular dos termos de troca brasileiros revisitada: 1850 a 2000. In: ENCONTRO NACIONAL DE ECONOMIA, 29., 
2001, Salvador, Bahia. Anais. Niterói: ANPEC, 2001. Disponível em:<http://www.anpec.org. br/encontro2001/artigos/200102286.pdf> . Acesso em 02 fev. 2016.

LACERDA, A. C. A crise internacional e a estrutura produtiva brasileira. Economia $\mathcal{E}$ Tecnologia, Curitiba, v. 9, n. 1, p. 5-18, 2013.

LAMONICA, M. T.; FEIJÓ, C. A. Indústria de transformação e crescimento: uma interpretação para o desempenho da economia brasileira nos anos 1990 e 2000. Economia $\mathcal{E}$ Tecnologia, Curitiba, v. 9, n. 1, p. 20-40, 2013.

MARÇAL, E. F. Há realmente uma tendência à deterioração dos termos de troca? Uma análise dos dados brasileiros. EconomiA, v. 7, n. 2, p. 307-329, maio/ago. 2006.

MARCONI, N.; ROCHA, M. Taxa de câmbio, comércio exterior e desindustrialização precoce: o caso brasileiro. Economia e Sociedade, Campinas, v. 21, n. 4, p. 853-888, 2015.

MEYER, T. R.; PAULA, L. F.; PIRES, M. C. C. Taxa de câmbio e balança comercial no Brasil: uma análise recente. In: ENCONTRO NACIONAL DE ECONOMIA, 37., 2011, Foz do Iguaçu. Anais. Niterói: ANPEC, 2011. Disponível em:<https://ideas.repec.org/p/anp/en2009/121. html >. Acesso em 10 fev. 2016.

NAKABASHI, L.; CRUZ, M.; SCATOLIN, F. Efeitos do câmbio e juros sobre as exportações da indústria brasileira. Revista de Economia Contemporânea, Rio de Janeiro, v. 12, n. 3, p. 433-461, 2008.

OREIRO, J. L.; LEMOS, B. P.; SILVA, G. J. C. A relação entre a elasticidade-renda das exportações, a taxa de câmbio real e o hiato tecnológico: teoria e evidência. Economia $\mathcal{E}$ Tecnologia, Curitiba, v. 3, n. 1, p. 97-108, 2007.

; MARCONI, N. Teses equivocadas no debate sobre desindustrialização e perda de competitividade da indústria brasileira. Revista NECAT, Florianópolis, v. 3, n. 5, p. 24-48, 2014.

PALMA, G. Four sources of de-industrialization and a new concept of the Dutch disease. In: OCAMPO, J. A. (Ed.). Beyond reforms. Palo Alto, CA: Stanford University Press, p. 71-116, 2005.

PREBISCH R. The economic development of Latin America and its principal problems. Economic Bulletin for Latin America, v. 7, p. 1-22, 1950.

SILVA, G. J. C.; MILANI, R. U. Taxa de câmbio real, indústria e crescimento setorial de longo prazo: uma análise empírica para a economia brasileira no período recente. Revista de Administração, Contabilidade e Economia da Fundace, Ribeirão Preto, SP, v. 7, n. 2, p. 64-79, 2016.

SINGER, H. W. The distribution of gains between investing and borrowing countries. The American Economic Review, v. 40, n. 2, p. 473-485, 1950.

SOUZA, F. E. P.; LUPORINI, V. Câmbio ou preços: o quê mais tem afetado as exportações brasileiras? UFRJ: Grupo de Conjuntura Econômica, 2011. (Texto para discussão do Instituto de Economia - UFRJ). 
SQUEFF, G. C.; ARAÚJO, V. L. D. Trajetória da taxa de câmbio e heterogeneidade estrutural na indústria brasileira. Brasília, DF: CEPAL; IPEA, 2013. (Textos para Discussão CEPAL-IPEA n. 50).

TOURINHO, O. A. F.; KUME, H.; PEDROSO, A. C. d. S. Elasticidades de Armington para o Brasil-1986-2002: novas estimativas. Brasília, DF: IPEA, 2003. (Texto para discussão, n. 0974).

VERÍSSIMO, M. P.; ARAÚJO, V. M. Desempenho da indústria automobilística brasileira no período 2000-2012: uma análise sobre a hipótese de desindustrialização setorial. Economia e Sociedade, Campinas, v. 24, n. 1, p. 151-176, 2015.

\section{Apêndice A - Especificação das Equações do Modelo Orani-GBR 6}

As formas funcionais dos principais grupos de equações do núcleo central do modelo Orani-GBR são apresentadas neste apêndice, juntamente com a definição dos principias grupos de variáveis, parâmetros e coeficientes. A convenção utilizada para notação considera letras maiúsculas representando os níveis das variáveis e letras minúsculas representando suas variações percentuais. Os sobrescritos ${ }^{1},{ }^{2},{ }^{3}$, ${ }^{4} \mathrm{e}^{5}$ referem-se aos cinco diferentes usuários (indústrias, investidores, consumidores, exportadores e governo) dos produtos. Os subscritos $i, j, s, v$ e $q$ representam, respectivamente, os produtos $(i=1, \ldots, 56)$, as indústrias $(j=1, \ldots, 56)$, a origem ( $=1,2)$, os fatores primários trabalho e capital $(v=1,2)$ e os tipos de fator trabalho $(q=1, \ldots, 8)$. Os insumos são identificados por dois subscritos: o primeiro assume os valores $1, \ldots, g$, para bens, $g+1$, para fatores primários, e $g+2$, para "outros custos" (basicamente, impostos e subsídios sobre a produção); o segundo subscrito identifica a origem do insumo, podendo ser de uma região doméstica $(s=1)$ ou importado $(s=2)$, ou proveniente de mão de obra $(v=1)$ ou capital $(v=2)$.

A seguir, apresentam-se essas equações:

a) demanda por insumos intermediários:

$$
\begin{gathered}
x_{(i s) j}^{1}=z_{j}-\sigma_{i j}^{1}\left(p_{(i s) j}^{1}-\sum_{s} S_{(i s) j}^{1} p_{(i s) j}^{1}\right)+a_{j}^{1}+a_{i j}^{1}+a_{(i s) j}^{1}-\sum_{s} S_{(i s) j}^{1} a_{(i s) j}^{1} \\
S_{(i s) j}^{1}=\frac{P_{(i s) j}^{1} X_{(i s) j}^{1}}{\sum_{s} P_{(i s) j}^{1} X_{(i s) j}^{1}}
\end{gathered}
$$

b) demanda por fatores primários:

$$
\begin{aligned}
& x_{(g+1, v) j}^{1}=z_{j}-\sigma_{(g+1, v) j}^{1}\left(p_{(g+1, v) j}^{1}-\Sigma_{s} S_{(g+1, v) j}^{1} p_{((g+1, v) j)}^{1}\right)+a_{j}^{1}+a_{(g+1, v) j}^{1} \\
& -\sum_{s} S_{(g+1, v) j}^{1} a_{(g+1, v) j}^{1}
\end{aligned}
$$

6 Este apêndice se baseia em Horridge (2006) e De Wet (2003). 


$$
S_{(i s) j}^{1}=\frac{P_{(g+1, v) j}^{1} X_{(g+1, v) j}^{1}}{\sum_{q} P_{(g+1, v) j}^{1} X_{(g+1, v) j}^{1}}
$$

c) demanda por trabalho de diferentes tipos:

$$
\begin{gathered}
x_{(g+1,1, q) j}^{1}=z_{j}-\sigma_{(g+1,1) j}^{1}\left(p_{(g+1,1, q) j}^{1}-\sum_{s} S_{(g+1,1, q) j}^{1} p_{(g+1,1, q) j) j}^{1}\right)+a_{(g+1,1, q) j}^{1} \\
-\sigma_{(g+1,1) j}^{1}\left(a_{(g+1,1, q) j}^{1}-\sum_{s} S_{(g+1,1, q) j}^{1} p_{(g+1,1, q) j}^{1}\right. \\
S_{(i s) j}^{1}=\frac{P_{(g+1,1, q) j}^{1} X_{(g+1,1, q) j}^{1}}{\sum_{q} P_{(g+1,1, q) j}^{1} X_{(g+1,1, q) j}^{1}}
\end{gathered}
$$

d) demanda das famílias:

$$
\begin{gathered}
x_{i}^{3}-q=\varepsilon_{i}(c-q)-\sum_{k} \eta_{i k} p_{k}^{3}+a_{i}^{1}+\sum_{k} \eta_{i k}\left(a_{k}^{3}+\sum_{s} S_{k s}^{3} a_{k s}^{3}\right) \\
x_{i s}^{3}=x_{i}^{3}-\sigma_{i}^{3}\left(p_{i s}^{3}-\sum_{s} S_{i s}^{3} p_{i s}^{3}\right)+a_{i s}^{3}-\sigma_{i s}^{3}\left(a_{i s}^{3}-\sum_{s} S_{i s}^{3} a_{i s}^{3}\right) \\
\varepsilon_{i}=\frac{\delta_{i}}{S_{i}^{3}} \\
\eta_{i k}=\frac{-\delta_{i} S_{k}^{* 3}}{S_{i}^{3}} \\
\eta_{i k}=-\varepsilon_{i}-\Sigma_{k \neq i} \eta_{i k} \\
S i^{3}=\frac{\bar{P}_{i}^{* 3} \bar{X}_{i}^{* 3}}{\sum_{k} \bar{P}_{i}^{* 3} \bar{X}_{i}^{* 3}} \\
S i^{3}=\frac{\bar{P}_{i}^{* 3} \theta_{i}}{\sum_{k} \bar{P}_{i}^{* 3} \bar{X}_{i}^{* 3}}
\end{gathered}
$$

e) demanda por insumos para a produção de capital fixo:

$$
\begin{gathered}
x_{(i s) j}^{2}=y_{j}-\sigma_{i j}^{2}\left(p_{(i s) j}^{2}-\sum_{s} S_{(i s) j}^{2} p_{(i s) j}^{2}\right)+a_{j}^{2}+a_{i j}^{2}+a_{(i s) j}^{2}-\sum_{s} S_{(i s) j}^{2} a_{(i s) j}^{2} \\
S_{(i s) j}^{1}=\frac{P_{(i s) j}^{2} X_{(i s) j}^{2}}{\sum_{s} P_{(i s) j}^{2} X_{(i s) j}^{2}}
\end{gathered}
$$

f) demanda por produtos de exportação:

$$
x_{i}^{4}-a_{i}^{4 q}=\gamma_{i}\left(p_{i}^{4}-\phi-a_{i}^{4 p}\right)
$$


g) outras demandas finais e demanda de margens:

$$
\begin{gathered}
x_{i s}^{5}=c_{r} h_{i s}^{5}+f_{i s}^{5} \\
x_{r 1}^{(i s) j k}=x_{(i s) j}^{k}+a_{r 1}^{(i s) j k}
\end{gathered}
$$

O Quadro 1 descreve as variáveis, os parâmetros e os coeficientes de todas as equações:

\begin{tabular}{|c|c|}
\hline Variável & Descrição \\
\hline$x_{(i s) j}^{1}$ & $\begin{array}{l}\text { Demanda do usuário } 1 \text { pelo bem i, de origem s, para uso na indústria } \\
\text { j. }\end{array}$ \\
\hline$z_{j}$ & Nível de atividade: produção corrente do setor j. \\
\hline$p_{(i s) j}^{1}$ & $\begin{array}{l}\text { Preço pago pelo usuário } 1 \text { pelo bem i, de origem s, utilizado na indús- } \\
\text { tria j. }\end{array}$ \\
\hline$a_{(i s) j}^{1}$ & $\begin{array}{l}\text { Mudança técnica relacionada ao uso do bem i, de origem s, pelo } \\
\text { usuário } 1 \text { na indústria j. }\end{array}$ \\
\hline$\overline{x_{(g+1, v) j}^{1}}$ & Demanda pelo fator primário $\mathrm{v}$ pela indústria $\mathrm{j}$. \\
\hline$a_{(g+1, v) j}^{1}$ & Mudança técnica relacionada ao uso de fator v pela indústria j. \\
\hline$x_{i}^{3}$ & Demanda das famílias pelo bem composto i \\
\hline$x_{i s}^{3}$ & Demanda das famílias pelo bem i de origem $\mathrm{s}$. \\
\hline $\mathrm{C}$ & Gasto total das famílias na região $\mathrm{r}$. \\
\hline Q & Número de famílias. \\
\hline$p_{k}^{3}$ & Preço geral do bem $\mathrm{k}$ consumido pelas famílias. \\
\hline$p_{i s}^{3}$ & Preço do bem i de origem s consumido pelas famílias. \\
\hline
\end{tabular}

Quadro 1 - Descrição das variáveis, parâmetros e coeficientes 


\begin{tabular}{|c|c|}
\hline Variável & Descrição \\
\hline$a_{i}^{3}$ & $\begin{array}{l}\text { Mudança nas preferências de consumo das famílias pelo bem com- } \\
\text { posto i }\end{array}$ \\
\hline$a_{i s}^{3}$ & $\begin{array}{l}\text { Mudança nas preferências de consumo das famílias pelo bem i de } \\
\text { origem s. }\end{array}$ \\
\hline$x_{i s}^{2}$ & $\begin{array}{l}\text { Demanda do bem i de origem s usado como insumo para a produção } \\
\text { de capital. }\end{array}$ \\
\hline$y_{j}$ & Capital fixo criado pela indústria j. \\
\hline$p_{(i s) j}^{2}$ & $\begin{array}{l}\text { Preço do bem i de origem s usado como insumo para a produção de } \\
\text { capital pela indústria j. }\end{array}$ \\
\hline$a_{(i s) j}^{2}$ & $\begin{array}{l}\text { Mudança técnica relacionada ao uso do bem i de origem s para pro- } \\
\text { dução de capital pela indústria j. }\end{array}$ \\
\hline$x_{i}^{4}$ & Demanda por produtos de exportações. \\
\hline$a_{i}^{4 q}$ & $\begin{array}{l}\text { Coeficiente técnico para mudança horizontal na curva de exporta- } \\
\text { ções. }\end{array}$ \\
\hline$a_{i}^{4 p}$ & Coeficiente técnico para mudança vertical na curva de exportações. \\
\hline$p_{i}^{4}$ & Preço doméstico dos produtos de exportações. \\
\hline$\phi$ & Taxa de câmbio. \\
\hline$x_{i s}^{5}$ & Outras demandas. \\
\hline$c_{r}$ & Mudança real na despesa das famílias. \\
\hline$h_{i s}^{5}$ & $\begin{array}{l}\text { Variável shift para mudança nas outras demandas em relação à de- } \\
\text { manda das famílias. }\end{array}$ \\
\hline$f_{i s}^{5}$ & $\begin{array}{l}\text { Variável shift para mudança nas outras demandas em relação à de- } \\
\text { manda das famílias. }\end{array}$ \\
\hline
\end{tabular}




\begin{tabular}{|c|c|}
\hline Variável & Descrição \\
\hline$x_{r 1}^{(i s) j k}$ & $\begin{array}{l}\text { Quantidade do produto } \mathrm{r} 1 \text { usado como margem no fluxo do produto i } \\
\text { de origem s para a indústria j para o propósito } \mathrm{k} \text {. }\end{array}$ \\
\hline$x_{(i s) j}^{k}$ & $\begin{array}{l}\text { Quantidade do produto i de origem s para a indústria j para o propó- } \\
\text { sito k. }\end{array}$ \\
\hline$a_{r 1}^{(i s) j k}$ & Coeficiente técnico de margem. \\
\hline$\sigma_{\ddot{y}}^{1}$ & $\begin{array}{l}\text { Parâmetro: elasticidade de substituição entre bens de origem domésti- } \\
\text { ca e importação na função de produção da indústria j. }\end{array}$ \\
\hline$S_{(i s) j}^{1}$ & $\begin{array}{l}\text { Coeficiente: share do custo total para o bem i, de origem s, usado pela } \\
\text { indústria j. }\end{array}$ \\
\hline$\sigma_{(g+1, v) j}^{1}$ & Parâmetro: elasticidade de substituição entre os fatores produtivos. \\
\hline$S_{(g+1, v) j}^{\mathrm{l}}$ & $\begin{array}{l}\text { Coeficiente: share do custo total para o fator produtivo v usado pela } \\
\text { indústria j. }\end{array}$ \\
\hline$\varepsilon_{i}$ & $\begin{array}{l}\text { Elasticidade-gasto da restrição de homogeneidade (simetria e agrega- } \\
\text { ção de Engel). }\end{array}$ \\
\hline$\eta_{i}$ & $\begin{array}{l}\text { Elasticidade-preço da restrição de homogeneidade (simetria e agrega- } \\
\text { ção de Engel). }\end{array}$ \\
\hline$S_{i}^{3}$ & Coeficiente: share do bem composto i no orçamento das famílias \\
\hline$S_{i s}^{3}$ & Coeficiente: share do bem i de origem s no orçamento das famílias. \\
\hline$\delta_{i}$ & Coeficiente: nível de subsistência de cada bem i. \\
\hline$\theta_{i}$ & $\begin{array}{l}\text { Coeficiente: share dos bens luxuriosos i no orçamento (marginal bud- } \\
\text { get shares). }\end{array}$ \\
\hline$S_{i}^{3}$ & $\begin{array}{l}\text { Coeficiente: share do bem i, de origem s, no custo total do bem i, } \\
\text { usado na produção de capital pela indústria j. }\end{array}$ \\
\hline
\end{tabular}

continua... 
conclusão.

\begin{tabular}{|c|c|}
\hline Variável & \multicolumn{1}{|c|}{ Descrição } \\
\hline$\gamma_{i}$ & Parâmetro: elasticidade-preço da demanda por exportações. \\
\hline
\end{tabular}

Fonte: Elaboração própria a partir de Horridge (2006) e De Wet (2003).

De acordo com Dixon e Rimmer (2002), a acumulação de capital físico e de investimento pode ser formalizada matematicamente da seguinte maneira:

$$
K_{j}(t+1)=K_{j}(t) *\left(1-D_{j}\right)+I_{j}(t)
$$

em que $K_{j}(t)$ é a quantidade de capital disponível na indústria j durante o ano $t ; I_{j}(t)$ é o investimento da indústria $j$ durante o ano $t$; e $D_{j}$ é a taxa de depreciação, tratada como um parâmetro conhecido.

Com estoque inicial de capital físico $\left[K_{j}(0)\right]$ e com mecanismo para determinar o investimento $\left[I_{j}(t)\right]$, a equação 1 pode ser usada para esboçar o caminho do estoque de capital em $\mathrm{j}$. Retirando-se os subscritos de tempo para simplificar a notação, tem-se :

$$
E_{t}\left[R_{0}(t)\right]=E E Q R O R_{j}+D_{j S E Q_{j}}
$$

na qual $E_{t}\left[R O R_{j}(t)\right]$ é a taxa de retorno esperada no ano $t$ para os proprietários de capital j; $E E Q R O R_{j}$ é a taxa de retorno de equilíbrio esperada, isto é, a taxa de retorno exigida para sustentar indefinidamente a taxa corrente de crescimento do capital em j; e $D I S E Q_{j}$ é a medida de desequilíbrio na taxa de retorno corrente de j.

Na maioria das aplicações de modelos dinâmicos de EGC, o mecanismo para se determinar o investimento em $j$ pode ser representado por:

$$
\begin{gathered}
E_{t}\left[R O R_{j}(t)\right]=-1+\frac{E_{t}\left[Q_{j}(t+1)\right]}{C_{j}(t)} * \frac{1}{1+r}+\left(1-D_{j}\right) * \frac{E_{t}\left[C_{j}(t+1)\right]}{C_{j}(t)} * \frac{1}{1+r} \\
E_{t}\left[\operatorname{ROR}_{j}(t)\right]=f_{j t}\left(\frac{K_{j}(t+1)}{K_{j}(t)}-1\right)
\end{gathered}
$$

em que $E_{t}$ denota a expectativa no ano $t ; R O R_{j}$ é a taxa de retorno do investimento na indústria j realizado no ano $t ; Q_{j}(\mathrm{t}+1)$ representam o retorno sobre o capital j no ano $t+1$; ré a taxa de juros; $C_{j}(t)$ é o custo de uma unidade extra de capital instalado na indústria $j$ no ano $t$; e $f_{j t}$ é uma função não decrescente. 
A equação 21 define a taxa de retorno esperada na indústria j no ano $t$ como valor presente de um real extra de investimento, isto é, um real de investimento compra $1 / C_{j}$ unidades de capital no ano t. Além disso, diante dessa equação, espera-se gerar uma renda no ano $t+1$ de $E_{t}\left[Q_{j}(\mathrm{t}+1)\right] / C_{j}(t)$ e reduzir a necessidade de gastos em investimento em $\left(1-D_{j}\right) * E_{t}\left[C_{j}(t+1)\right] / C_{j}(t)$. A equação 22, por sua vez, define uma curva de oferta-investimento e mostra que a taxa de retorno exigida pelos investidores quando estes gastam um real extra na indústria $j$ depende da taxa de crescimento do estoque de capital $j$. Essa equação tem por hipótese a redução da disponibilidade de fundos de investimento de tal modo que, diante da inclinação positiva da função $f_{j t}$, a indústria $j$ atrai consideráveis fundos de investimento, dado uma alta taxa de crescimento do capital e, com isso, provoca a alta na taxa esperada de retorno para atrair o investidor marginal. Cabe notar que é usual assumir-se que a oferta de fundos de investimento é infinitamente elástica em relação à taxa de juros.

O mercado de trabalho pode ser definido matematicamente como:

$$
\frac{\Delta w}{w_{0}}=\gamma\left(\frac{L_{0}}{T_{0}}-1\right)+\gamma \Delta\left(\frac{L}{T}\right)
$$

em que: $L$ corresponde ao nível de emprego atual; $T$ representa o nível de emprego tendencial; e $w$ refere-se ao salário real.

Recebido em: 30/11/2016. Aceito em: 16/08/2017. 